\title{
A Qualitative Analysis of the Stepparent Role on Transition Days in Blended Families
}

\author{
Charity Perry-Fraser, Rick Fraser \\ Sociology Department, California State University Los Angeles, Los Angeles, USA \\ Email: cperry5@exchange.calstatela.edu
}

How to cite this paper: Perry-Fraser, C. and Fraser, R. (2018) A Qualitative Analysis of the Stepparent Role on Transition Days in Blended Families. Open Journal of Social Sciences, 6, 240-251. https://doi.org/10.4236/jss.2018.68020

Received: April 28, 2018

Accepted: August 24, 2018

Published: August 27, 2018

Copyright $\odot 2018$ by authors and Scientific Research Publishing Inc. This work is licensed under the Creative Commons Attribution International License (CC BY 4.0).

http://creativecommons.org/licenses/by/4.0/

\section{(c) (i) Open Access}

\begin{abstract}
The current qualitative research study enhances the understanding of stepparent roles on transition day for researchers and clinicians who focus on marriage and family issues. Thirteen family members (parents, stepparents) who were in various stages of stepfamily formation were assessed. The current study explicated three themes of the stepparent role on transition day. The themes were: stepparent role and authority, stepparent role and ambiguity, and lastly, stepparent role and single to having children. By gaining a more in-depth understanding of stepparent roles during days of transition, immediate assistance may be provided to families who encounter transition difficulties. Useful approaches for current and future stepfamilies are discussed.
\end{abstract}

\section{Keywords}

Stepparent Roles, Blended Families, Stepfamily, Transition Daze, Transition Day, Stepparent

\section{Introduction}

The purpose of the current study was to determine the roles of stepparents on transition days. The Pew Research Center on adults in America [1] noted that $42 \%$ (95.5 million) of adults have a step-relationship consisting of a stepparent, step or half sibling, or stepchild. Nationally, $13 \%$ of adults are stepparents (2930 million), 15\% (16.5 million) of men are step-dads, and 12\% (14 million) of women are stepmoms. The purpose of the current study was to gain greater understanding of the stepparent role on transitional days in stepfamilies. Researchers argue the challenges faced by stepfamily members typically revolve around the role of the stepparent [2] [3] [4]. The researchers also argue the most difficult of relationships lie between the stepparent and stepchild mainly because 
these relationships are involuntary which leaves minimal motivation for these members to create close bonds [5]. Families unknowingly may feel bewildered by what the researchers call "the transition daze" [6]. During days of transition, when families are in the process of transferring children from home to home, a stepparent role may also be lost in the shuffle. Previous research concluded serial transitions in and out of marriage/divorce/cohabitation are now typical of family life in the United States [4] but only recently have transition days been discussed [6].

The first several years following formation of a stepfamily can often be turbulent [3]. Remarriages risk for divorce during the first five years is prevalent [7]. Reducing the conflict in hopes of preventing a family dissolution should be the primary focus of stepfamily research. Interventions, which assist children who are involved in the often conflictual transition between remarried partners, is of great need.

This study was developed to create a greater understanding of stepparent roles and development during days of transition by reviewing issues that arise in the stepfamily during and the roles of stepparents during such transitions and provides research results applicable to the field of marriage and family therapy and provides narratives of thirteen stepfamily members interviewed. Experiences were recorded by interviewing biological parents and stepparents of reconstituted families.

Stepfamilies are more common in the United States than any other country [8]. A primary interest of stepfamily researchers has been on the demographic shifts our nation has experienced. However, blended families tend to have more conflict, likely to experience more crises, recover more slowly from crises than traditional families [9]. Stepparents and stepchildren must work unceasingly to develop new bonds [10]. These bonds are interrupted for many blended families on a weekly basis when the child(ren) must return to their other custodial home [6]. Therefore, it is essential for stepparents to have realistic expectations about the length of time required to establish roles, and also reestablish roles during each transition. Through this work, a family's natural pattern of functioning can be determined [10] [11]. The main research question of this study while considering there are different processes involved when moving from a custodial parent's home to a non-custodial parent's home and vice-versa [6] [12] and what roles can be elicited from data mining of interviews on the distinct content of stepparent roles during transition days.

\section{Review of Literature}

\section{Theoretical Approaches to Stepfamily Transition Research}

Some functions of theory were detailed by researchers [13] who found that systems theory and role theory were the most explicitly used theories in adolescent and stepparent research. The researchers also argue that researchers have a responsibility to describe the theory they are using in research explicitly to the 
readers, and argue theories provide knowledge and contribute to science [14].

Role Theory. Role Theory has been cited in numerous articles about stepfamily research. Researchers [15] [16] found the degree of stress involving stepfamily formation depends on the resources each individual brings to the new family structure. In this context, the studies both focused on stepmothers and stepchildren. Researchers [17] used role theory for their research on the relationship between stepfathers and adolescents. The researchers focused on three concepts of role theory: anticipatory socialization, role conflict and role reciprocity.

Coping Theory. Coping theory has been utilized in various stepfamily research articles. Previous researchers [18] [19] all linked their findings to coping theory, specifically focusing on ego-psychological theory application to investigate the resources individuals use to cope with stress.

Family Systems Theory. The family as a whole is greater than the sum of its parts. We know that each family is unique in its structure, expected roles, rules, goal, and boundaries. Family System Theory argues that if a family can reconcile all of these within its system that it can achieve homeostasis and grow beyond the stagnation that can occur when there is rapid change which can create instability and disharmony. Family Systems Theory first evolved in the 1960s and 1970s [2] [20] [21] [22].

Transition Theory. Transition theory has been used in previous research of stepfamilies to discuss the difficulties transitions such as adolescence and remarriage [23]. Other researchers [24] used transition theory has been argued it integrates psychological and family systems literature to assess self-esteem and communication with a stepparent. Although this particular study focused on adolescents, it can be applied in a broad manner when considering stepchildren of all ages and their relationships with biological and stepparents.

Past researchers [25] [26] have conducted in-depth stepparent interviews and stepchildren and found stepparents who attempted to bond with stepchildren before marriage on a regular basis are more likely to have a positive bond than those who stop bonding after re-marriage. Other qualitative research [27] has examined the roles of father and stepfathers working together for the benefit of the children and the overall family relationships.

\section{Methodology}

\subsection{Participant Selection}

Qualitative researchers have the unique position of being interpretive researchers. We have purposefully selected participants who are actively in a stepparent role. Selection criteria used for the current research: a) The interviewee was a parent in a blended family or stepfamily, and b) The interviewee was open and willing to discuss their experiences about transitional days in stepfamilies.

\subsection{Procedures}

Private, one-on-one, semi-structured interviews were conducted to ensure the 
interviewee could tell their story without interruption and to ensure sensitivity to the interviewee's emotional state. Interviewees answered demographic questions prior to the interview. Every effort was made to build trust with the interviewee in order to establish openness between the interviewer and interviewee. The same questions were asked of each participant. Narratives were analyzed carefully for information on stepparent roles during days of transition transitional days in blended families.

\subsection{Data Analysis}

Each interview considered individually in the analysis. Common themes relating to stepparent roles on days of transition were identified across the interviews.

\subsection{Limitations}

Different interpretations of the material was possible. Such subjectivity could have led to a second limitation, generalizability of results. The subjective nature of the current study minimizes generalizability to a larger population. Personal biases may have influenced participant responses just as changing demographics and backgrounds of the interviewee's. The current study's questions varied in interpretation for interviewees, who had different cultural backgrounds, age, education attainment and race. The current study used narrative inquiry interviewing which also carries strengths and weaknesses. Strengths of narrative inquiry: collaboration, it gives a "voice" to researchers, it helps others understand the topic, and lastly, it captures everyday data that many may relate to. Some weaknesses of narrative inquiry is that interviewees may reply to questions in an insincere manner, as researchers assume that interviewees are speaking for themselves, but they may fail to acknowledge the social and cultural accounts that pertain to their individual accounts.

\subsection{Summary of Demographics}

Thirteen interviewees consented for this study, all participants were involved in a family unit that met the criteria. There was an age range in participant's of 30 years old to 69 years old, and $38 \%$ of interviewees fell in the range of 30 years old to 39 years old. Nine participants categorized themselves as female, and four male. Interviewees had diverse ethnic backgrounds: Caucasian, African-American, Asian, and Latino/Latina; $46 \%$ of the interviewees were Caucasian. All interviewees identified themselves as a biological parent in a blended family unit or a stepparent to a child in a blended family unit. Interviewees categorized themselves in religious categories which included: Buddhism, Catholic/Christian, Islam, Hindu, Jewish, Muslim, Sikh, other religion and no religion. The interviewees identified the following religions from the categories listed above Catholic/Christian, Buddhism, Christian, or no religion. Specifically, $30 \%$ of the interviewees were Catholic/Christian, 30\% Christian, 15\% Buddhism, 15\% no religion and 10\% identified as Buddhist/Catholic/Christian. Educational attainment 
was assessed and 38\% reported completion a graduate degree, 30\% reported completion of a four-year degree, $15 \%$ reported completion a post-graduate degree, $10 \%$ reported completion of a two-year degree, and $10 \%$ reported completion of high school. Occupations reported to the researchers were: banker, talent agent, registered nurse, administrator, paralegal, tennis coach, musician, yoga teacher, student, writer, office manager and physician.

Of the interviewee's $70 \%$ were previously married and $30 \%$ had never been married. Length of previous marriages ranged from 4 years to 14 years. Not every interviewee had children from a previous relationship. The ages of the children ranged from 5 years old to 37 years old.

The time a child spent with the interviewee's family was $20 \%-100 \%$. The children who spent $100 \%$ of the time with the custodial parent was still in contact with the non-custodial parent from time to time. The current study also elicited information about the other parent of the child and found that $40 \%$ of previous spouses remarried, with remarriage time ranging from ten days to four years. Children spent $54 \%$ of their time in these homes and children ranged from 6 years old to 19 years old.

Questions addressed during the interviews elicited information on whether or not cohabitation occurred with the current family unit with the current spouse/partner before marriage; $53 \%$ of the interviewees cohabitated before blending the current family unit. Also noted, was the age range of the children's at the time of cohabitation/marriage and the ages ranged from 2 years old to 17 years old.

\subsection{Demographic Characteristics of Interviewees}

The current study elicited data from thirteen interviewees which included the participant's age, sex, ethnicity, religious preference, current occupation, and level of educational attainment, as well as the age of the children and partner's children at the time of marriage/cohabitation.

\section{Data Analysis Findings}

The current findings elicited information described by the participants from their experiences and perspectives of their roles as stepparents on transition days. The stepparent roles were identified in the current research and classified further into themes: authority, ambiguous role, and single to married having kids difficult. As shown in Table 1.

Theme 1: Authority. Interviewees referenced sharing authority, while others felt a lack of authority over their stepchildren. Participant 6 shared how she

Table 1. Theme frequency for research questions.

\begin{tabular}{ccc}
\hline Themes of Stepparent Role & N Mentioning & Exemplar Quotes \\
\hline Authority & 6 & 13 \\
Ambiguous role & 5 & 6 \\
Single to having kids difficult & 4 & 5 \\
\hline
\end{tabular}


became a primary caretaker for her stepchildren, saying:

"When my husband would be gone for long periods of time and come back and try to start making the rules or making the decisions, I didn't feel like he valued, or gave me enough respect in those decisions."

Participant 2 described enforcing the stepmother's authority over his biological children, saying:

"And I've discussed it with the kids at length that, you know, in my household my partner is an adult, she is a parent, and she has every bit as much say in the way things go as the way I do."

Participant 7 however, felt differently, saying, "I do not feel the responsibility or the desire to take them under my wing and parent my stepchildren in any sort of way you know that I would impose on them."

Theme 2: Ambiguous role. Interviewees referenced the role of a stepparent as being ambiguous and not always simple to define. Participant 10 shared:

"The dynamic is too crazy and you're trying as a, you know, as a stepmom I felt like I didn't want to overstep my bounds but yet I didn't want to seem like was aloof either. So it's really hard. It was really hard for me to find my place with the boys."

Participant 1 shared:

"I think it's tough for the women, for the step mom, to realize that we are the secondary parent, and the, and we cannot be the primary parent. The kid will have resentment about it, you know, I think the kid does not want someone to replace their mom."

Theme 3: Single to having kids difficult. Interviewees referenced difficulty of transition from a single person to having an entire family with children.

Participant 13 said:

"You know probably just getting used to the responsibility of just being, you know, a mom of. And my son came in 2003, so two years later, I had a baby. So, just being-just getting used to all the responsibility of running a household."

Participant 7 shared, "Uh, you know I lived by myself for a-a long time and I'm a quiet person um, and his kids are very extroverted. They like to be around all the time."

\subsection{Conclusion}

Through qualitative methods of data analysis, the researchers elicited the voices of interviewees and developed the themes in the previous section. The current study focused on the stepparent roles on transition day with the knowledge there are different processes involved when moving from a custodial parent's home to a non-custodial parent's home and vice-versa. The current study concluded 
there are three sub-themes of the stepparent role which was further addressed by examples given to convey the themes provided by each participant.

\subsection{Summary of Findings}

Theme 1: Stepparent Role and Authority. Interviewees described the sharing of authority, while others described how they felt a lack of authority over their stepchildren. It was referenced thirteen times in six interviews. Some interviewees became the primary caretaker of their stepchildren and had spouses who traveled. Those spouses, however, would attempt to re-enter the household after a long period of time. In such situations the primary caretaker did not feel respected as an authority figure. Other interviewees felt they should rally around their partner and step up for their partner by telling their children the stepparent had as much authority as they did in the household. Another interviewee did not feel the desire or responsibility to parent the children.

Theme 2: Stepparent role and ambiguity. Interviewees described the role of the stepparent as being ambiguous and not always simple to define. Some interviewees shared their difficulties around boundaries, not wanting to over step them or seem too aloof. Another interviewee described that it is difficult for step-moms because they are the secondary parent and cannot be the primary parent. That interviewee expressed how the children did not want someone to replace their mom.

Theme 3: Stepparent role and single to having children. The third theme of the stepparent role them was described by interviewees who found it difficult to transition from being a single person to having an entire family with children. Interviewees referred to the difficulties of transitioning from being a single person to having an entire family with children. One interviewee took time to get used to the idea of running a household and responsibility of being a mom. Another one struggled with the personality conflicts with the stepchildren, who were extroverts.

\subsection{Discussion}

This study was intended to explore and develop a fundamental understanding of the stepparent role on transition days in stepfamilies. Dominant themes elucidated from the analysis were stepparent role and authority, stepparent role and ambiguity, difficulty from being single with not children to having children.

The parents (bio/step) interviewed for the current study were in various stages of stepfamily/blended family formation. They provided valuable insight for individuals who are involved in a stepfamily/blended family environment.

\section{Interpretation of Findings}

The current research uncovered three themes identifiable in trying to understand the role of a stepparent on transition day. The first theme elucidated was the stepparent role and authority, which was defined by the ability to re-establish 
an authoritative role after a child has been parented by another family system or a stepparent following an absence by a biological parent. These absences could have occurred during the normal course of a work day, when a parent traveled frequently, or when a parent was minimally engaged with maintaining the structure of the family. Stepparents who take on the role of disciplining their stepchild when the biological parent is away must often relinquish that role when the biological parent returns. If the biological parent does not recognize the change that he/she brings when they reenter the family system, authority still shifts from one parent to another but it is not likely to be in the most efficient or empathic manner. This leaves the stepparent in the dilemma of having all of the responsibility, and conflicted authority to carry out what has been previously agreed upon.

Such a confusion of authority created transitional issues that parents interviewed had a difficult time overcoming. In the worst cases, newly constituted families who reported issues with authority had to recapitulate in order to achieve successful transitions between the two families. This confusion of authority also had an impact on the marital dyad and parent-child dyads. Individuals in the current study reported that confusion resulted from a lack of personal support between parents. This disconnect between parents was exploited by children, who were already ambivalent about the roles and authority maintained by stepparents. Thus, when a stepparent does not feel supported, unforeseen changes in the family system may have a profound effect on the step-parent child relationship.

This observation is analogous to what has been expressed by military families (e.g., Navy families) in which long tours of duty create an absence that necessitates one parent having greater authority over the children while the other parent is away. Following the return of the absent parent, the family must readjust to accommodate the parent's return. Yet, stepfamilies are different from military families because the stepparent usually does not have the same bonded relationship with the child as does the biological parent. This creates an added level of dissonance for stepparents as they take on responsibility for the care of the children and may feel usurped in their own authority. Hence, parental awareness about how authority is transferred between stepfamilies remains an important issue not only during transitional days, but also in the days that follow.

The second theme of stepparent role, was ambiguous role. Ambiguity in this sense was the result of unclear roles created by numerous issues in the newly reconstituted family. The ambiguous role of the stepparent can be the result from a lack of agreement in the parental dyad, lack of an authoritative figure in raising the children, uncertainty caused by conflict in the new family, and/or multiple circumstantial events that are external to the families internal working (i.e., job conflicts, financial difficulties). In this case, the problem is not one of shifting authority from one person to another; rather the difficulty is there may be no clear boundaries regarding issues such as: child care, discipline, or expectations 
of the children.

Stepparents are often unwilling to play a primary role in the discipline of non-biological children. However, not following through with clear boundaries can create a confusing and chaotic environment for a child. Not being able to rely on a stepparent in the same way they rely on the biological parent means the child must internalize ambiguity. This creates emotional confusion and distress within a child, which can precipitate behavior that becomes even more dissonant. This creates behavior that a stepparent may have difficulty in containing, and therefore create a cycle of escalation that must be addressed by the family unit. If no one is willing to step up and respond to the anxiety created by such ambivalence, then children will be left to their own devices to create their own emotional defenses to guard against the feelings of confusion, anxiety or perhaps annihilation experienced. The long-term consequences of an ambiguous relationship with a child are, to some extent, similar to a neglecting or capricious parent. Children need consistency, stability and unconditional empathy in stepfamilies or blended families; breaches of any of these characteristics will lead to a much more fragile family system.

The last theme of the stepparent role, refers to a stepparent who has never had children entering into a relationship in which they are now responsible for the children of their partner. The newly added parent to any family system has a great amount of ground to make up. Not only must the new parent learn to be a marriage partner and readjust to a marital dyad, but they must learn to play the role of a parent. The study interviews indicated there were multiple concepts that had to be learned by the new parents. Primary among these was how to manage the transitional day and the other spouse. Thus, the newly added parent must act not only as an authoritative figure for the children, but must do so in front of and while being scrutinized by the children's biological parent. In the best scenario, the biological but non-custodial parent is supportive of this new role and is able to communicate this to the children in a loving and generous manner. More than likely however, the non-custodial biological parent has already established their own emotional and behavioral standards for the children and the newly added parent must learn and adopt those standards. If there is role conflict between the two biological parents, the newly added parent must recognize both sets of rules and seek to negotiate a common ground by which to establish themselves as an authoritative figure to the children. The complexity of this task is apparent; children may already have divided loyalties when having to choose between two biological parents who have mutually exclusive ideals. A third figure, at the very least, complicates the matter. All of this takes place within an emotional, systemic relationship and may be experienced as confusing. In other words, this is not a theoretical concept but an experiential concept. Newly added parents face the responsibility to create a separate authoritative relationship with the children and yet they are third in line in terms of emotional and/or rational connection with the children. 
Another issue of adopted authority for the newly added parent is how their own personality characteristics interact with those of the biological parents. If the new parent's personality is more assertive than either of the biological parents, then the newly added parent may feel a tremendous amount of cognitive dissonance about having to remain in the background. In this way the new parent may become a de-facto policeperson who must enforce rules even when she/he does not have well developed relationships with the parents and children. These individuals may feel some level of helplessness because the harder they try the more alienated they become from either family system. Psychologically speaking, it is a no win situation.

In summary, stepparents take on multiple and diverse roles. They must acclimate to a system that has existed previously; such acclimation processes can be classified as authoritative, ambiguous, or newly added. These stepparents seek to find a balance between their previous roles and the new responsibilities they must take on. Competence in a previous life does not necessarily translate into competence in negotiating the new family system. The family system must also shift to adapt to the personality of the newly added parent. This adaptation can be either positive or negative as any adaptation can be conflictual and unstable.

\section{Advice for Current or Future Stepfamily/Blended Family Members}

The stepparent role is one of the greatest challenges facing those in a remarriage situation. Children sometimes react very negatively thereby making it difficult for the involved parties to establish relationships that are comfortable. Creating the opportunity to develop a meaningful relationship with one's stepchild and allowing one's partner to develop a relationship benefits the remarried family. As these relationships are established, there is likely to be less conflict associated with the child. This includes being respectful of the relationship a former spouse has taken on. Children by nature are much more willing to accept another person when they have 'permission.' Upon interview completion, participants were asked to provide advice for future blended families. The following suggestions were mentioned: the importance of being patient was repeated by almost all interviewees; be thoughtful; do not linger during transition times with long goodbyes; many found it helpful to transition at school so only one parent was present; observe without reacting quickly; try to be emotionally flexible; keep communication open for children to help them acknowledge their feelings, and make sense of their feelings; and finally, not to take things personally.

\section{Limitations of Current Study}

Limitations associated with this study was recognizing qualitative research, especially narrative inquiry, can have multiple interpretations, which may be dependent upon researcher's biases and past experiences. The second limitation was generalizability. Arguably, the subjective nature of the current study mini- 
mizes generalizability to a larger population. The third limitation was the researchers' personal biases may have influenced how participants responded. There was considerable variability in the demographics and backgrounds of the interviewee's therefore leading interpretation of the questions posed in this study to have differ among participants because of an individual's culture, age, and educational attainment.

\section{Future Research}

Future research on transition days in stepfamilies or blended families should include more qualitative studies that focus specifically on the transition days in families such as the formation of relationships between stepparents and their stepchildren and how they can reconnect after having been apart. It would be beneficial that biological parents not interrupt this process and let it occur naturally.

\section{Conflicts of Interest}

The authors declare no conflicts of interest regarding the publication of this paper.

\section{References}

[1] Parker, K. (2011) A Portrait of Stepfamilies. Pew Social Trends. http://pewsocialtrends.org/2011/01/13/a-portrait-of-stepfamilies/

[2] Bowen, M. (1978) Family Therapy in Clinical Practice. Jason Aronson, New York.

[3] Bray, J.H. and Kelly, J. (1999) Stepfamilies. Random House Digital, Inc., New York.

[4] Cherlin, A.J. (2010) The State of Marriage and the Family in America. Vintage, New York.

[5] Ganong, L.H. and Coleman, M. (1994) Remarried Family Relationships. Sage, Thousand Oaks, CA.

[6] Perry-Fraser, C. and Fraser, R. (2016) Transition Daze: A Qualitative Analysis of Transition Days in Blended Families. Psychology, 7, 1110-1118. https://doi.org/10.4236/psych.2016.78111

[7] Clarke, S.C. and Wilson, B.F. (1994) The Relative Stability of Remarriages: A Cohort Approach Using Vital Statistics. Family Relations, 43, 305-310. https://doi.org/10.2307/585422

[8] Sweeney, M.M. (2010) Remarriage and Stepfamilies: Strategic Sites for Family Scholarship in the $21^{\text {st }}$ Century. Journal of Marriage and Family, 72, 667-684. https://doi.org/10.1111/j.1741-3737.2010.00724.x

[9] Schlomer, G.L., Del Giudice, M. and Ellis, B.J. (2011) Parent-Offspring Conflict Theory: An Evolutionary Framework for Understanding Conflict within Human Families. Psychological Review, 118, 496. https://doi.org/10.1037/a0024043

[10] Visher, E.B., Visher, J.S. and Pasley, K. (2003) Remarriage Families and Stepparenting. Normal Family Processes. Growing Diversity and Complexity, 3, 153-175.

[11] Hetherington, E.M. and Kelly, J. (2003) For Better or for Worse: Divorce Reconsidered. W. W. Norton \& Company, New York.

[12] Perry-Fraser, C. and Fraser, R. (2017) A Qualitative Analysis of Difficulties on 
Transition Days in Blended Families. Advances in Applied Sociology, 7, 245-259. https://doi.org/10.4236/aasoci.2017.76015

[13] Robila, M. and Taylor, A.C. (2001) The Recent Use of Theory within Stepparent and Adolescent Relationship Research. Journal of Divorce and Remarriage, 35, 81-92. https://doi.org/10.1300/J087v35n03_05

[14] Klein, D.M. and White, J.M. (1996) Family Theories: An Introduction. Sage Publications, Thousand Oaks, CA.

[15] Quick, D.S., Newman, B.M. and McKenry, P.C. (1995) Influences on the Quality of Stepmother Adolescent Relationship. Journal of Divorce and Remarriage, 24, 99-114.

[16] Quick, D.S., McKenry, P.C. and Newman, B.M. (1994) Stepmothers and Their Adolescent Children: Adjustment to New Family Roles. In: Paisley, K. and Ihinger-Tallman, M., Eds., Step Parenting. Issues in Theory, Research and Practice, Greenwood, Westport, 105-125.

[17] Skopin, A.R., Newman, B.M. and McKenry, P. (1993) Influences on the Quality of Stepfather Adolescent Relationships: View of Both Family Members. Journal of Divorce and Remarriage, 19, 181-196. https://doi.org/10.1300/J087v19n03_12

[18] Needle, R.H., Su, S.S. and Doherty, W.J. (1990) Divorce, Remarriage, and Adolescent Substance Abuse: A Prospective Longitudinal Study. Journal of Marriage and the Family, 52, 157-169. https://doi.org/10.2307/352847

[19] Whitsett, D. and Land, H.M. (1992) Role Strain, Coping, and Marital Satisfaction of Stepparents. Families in Society: The Journal of Contemporary Human Services, 73, 79-92. https://doi.org/10.1177/104438949207300202

[20] Minuchin, S. (1974) Families and Family Therapy. Harvard University Press, Cambridge.

[21] Satir, V. (1967) Conjoint Family Therapy. Science and Behavior Books, Palo Alto.

[22] Satir, V. and Baldwin, M. (1983) Satir Step by Step. Science and Behavior Books, Palo Alto.

[23] Grinwald, S. (1995) Communication-Family Characteristics: A Comparison between Stepfamilies (Formed after Death or Divorce) and Biological Families. Journal of Divorce and Remarriage, 24, 183-196.

[24] Collins, W.E., Newman, B.M. and McKenry, P.C. (1995) Intrapsychic and Interpersonal Factors Related to Adolescent Psychological Well-Being in Stepmother and Stepfather Families. Journal of Family Psychology, 9, 433-445.

https://doi.org/10.1037/0893-3200.9.4.433

[25] Ganong, L.H., Coleman, M., Fine, M. and Martin, P. (1999) Stepparents' Affinity-Seeking and Affinity-Maintating Strategies with Stepchildren. Journal of Family Issues, 20, 299-327. https://doi.org/10.1177/019251399020003001

[26] Ganong, L.H., Coleman, M. and Jamison, T. (2011) Patterns of Stepchild-Stepparent Relationship Development. Journal of Marriage and Family, 73, 396-413. https://doi.org/10.1111/j.1741-3737.2010.00814.x

[27] Marsiglio, W. and Hinojosa, R. (2007) Managing the Multifather Family: Stepfathers as Father Allies. Journal of Marriage and Family, 69, 845-862. https://doi.org/10.1111/j.1741-3737.2007.00409.x 